\title{
Serum and synovial fluid adenosine deaminase activity in patients with rheumatoid arthritis, osteoarthritis, and reactive arthritis
}

\author{
H YUKSEL AND T F AKOGLU \\ From the Department of Medicine, Marmara University, Medical School, Istanbul, Turkey
}

SUMmaRY Adenosine deaminase activity was determined in paired samples of serum andos synovial fluid taken from patients with rheumatoid arthritis $(n=12)$, reactive arthritis $(n=13), \stackrel{i}{\mathrm{~N}}$ and osteoarthritis $(n=7)$, and the value of this investigation in the diagnosis of synovial swellingso was assessed. Increased activity was found in the synovial fluid taken from patients with ${ }^{\supset}$ rheumatoid disease and reactive arthritis, though values were less raised in the latter. Synovialc fluid taken from patients with osteoarthritis did not show significantly raised adenosine deaminase activity as compared with that of normal controls $(n=3)$.

Key words: rheumatoid effusions.

Adenosine deaminase (ADA) is one of the main enzymes of the purine metabolic pathway, catalysing the deamination of adenosine to inosine and deoxyadenosine to deoxyinosine. During inflammatory reactions the enzyme is released into the extracellular fluid, and in serous effusions of differing pathology the levels of ADA activity increase considerably. This increase has been shown to correlate with the number of nucleated cells, particularly $\mathrm{T}$ lymphocytes and macrophages, present in the effusions. ${ }^{12}$

It has also been shown that pleural effusions due to rheumatoid arthritis (RA) or tuberculosis contain significantly higher levels of ADA than effusions caused by systemic lupus erythematosus or malignant diseases. ${ }^{3-5}$ This has led to the proposal that determination of ADA activity may be a useful technique when the aetiology of pleural, pericardial, or ascitic fluids is under investigation. ${ }^{6-8}$

We have investigated ADA activity in paired samples of serum and synovial fluid obtained from patients with rheumatoid arthritis, reactive arthritis, and osteoarthritis to assess the value of the test in the differential diagnosis of joint swellings.

\section{Patients and methods}

Three groups of patients were investigated and

Accepted for publication 25 November 1987.

Correspondence to Dr T F Akoğlu, Marmara University, Medical School, Department of Medicine, Altunizade, Istanbul, Turkey. compared with a control group. The first group consisted of 12 patients with classical rheumatoid arthritis according to the American Rheumatism $\overrightarrow{\vec{B}}$ Association criteria. Seven of these patients were 3 seropositive and five seronegative. The synovial fluid of three of the seronegative patients containedô rheumatoid factor, however, and these individuals were also regarded as seropositive. Two patientso were male, 10 female, with ages ranging between $25 \%$ and 66 years (mean 42). All the patients with RA were suffering active disease at the time of theo investigation; they were complaining of morning stiffness and pain and they had synovial swellings and increased sedimentation rate.

The second group consisted of seven patients with osteoarthritis, of whom three had a history of joint trauma. Three patients were male, four female, with ages ranging from 36 to 67 years (mean 57). These patients were rheumatoid factor and antinuclear $\omega$ factor negative, with normal sedimentation rates?

The third group consisted of 13 patients sufferinge reactive arthritis. Ten patients were male, threes female, with a mean age of 19 . Seven of these patients had brucellosis, three had rheumatic fever, $\frac{0}{-}$ while the remaining patients suffered from sickle cell disease, toxoplasmosis, and meningococcal sep $-\frac{\Omega}{\square}$ ticaemia.

Normal synovial fluid for control purposes waহ obtained from three cadavers at necropsy. These individuals had abdominal pathologies and no clini定 
cal signs of joint involvement. Synovial fluids were aspirated within three hours of death.

Normal serum for control purposes was collected from 10 healthy laboratory personnel.

Paired serum and synovial fluid samples were obtained from the patients and stored at $-25^{\circ} \mathrm{C}$ for ADA determination. In addition to the routine laboratory investigations which were performed on all samples, synovial fluids were examined for the presence of crystals and rheumatoid factor. Routine microbiological cultures of synovial fluid samples were obtained and total white cell count and the percentage of the lymphocytes were determined also.

ADA activity was determined according to the method described by Karger ${ }^{9}$ with minor modifications. Serum or synovial fluid $(2 \mathrm{ml})$ was mixed with $1.0 \mathrm{ml}$ of adenosine substrate $(0.4 \%$ adenosine in $0.6 \mathrm{M}$ phosphate buffer $\mathrm{pH} 6.4$ ) and $2 \mathrm{ml}$ of this mixture was incubated at $37^{\circ} \mathrm{C}$ for one hour. Trichloroacetic acid (TCA; $1 \mathrm{ml} 0.6 \mathrm{M}$ ) was added to the remaining $1 \mathrm{ml}$ of the mixture and kept at room temperature as a negative control. At the end of a one hour incubation period $2 \mathrm{ml}$ of TCA was added to the test samples to stop the reaction. The test tubes containing test and control samples were centrifuged and $0.25 \mathrm{ml}$ of supernatants from each of the tubes was transferred to fresh tubes. To each of the supernatants, $2.5 \mathrm{ml}$ of phenol colour reagent

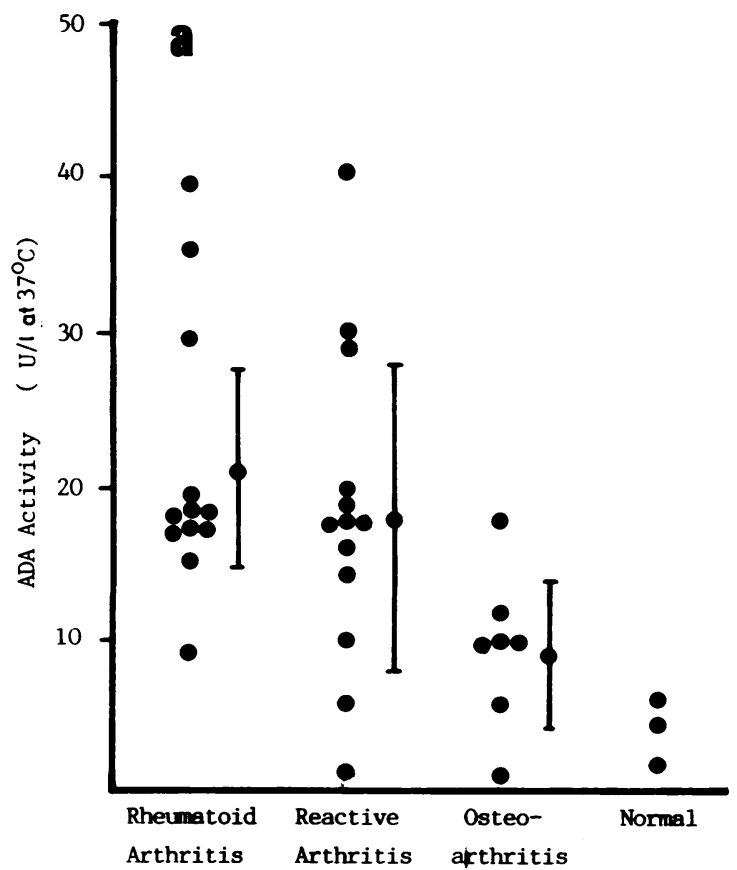

$(0.01 \%$, sodium nitroprusside and $1 \%$ phenol in water), $0.1 \mathrm{ml}$ of $1 \mathrm{M} \mathrm{NaOH}$ solution, and $2.5 \mathrm{ml}$ of alkaline hypochlorite solution $(0 \cdot 5 \% \mathrm{NaOH}$ and $2 \mathrm{ml}$ of $2 \cdot 1 \%$ hypochlorite in water) were added. Samples were incubated for a further 20 minutes at room temperature and colour developed was estimated spectrophotometrically at $660 \mathrm{~nm}$ against water blanks.

Diammonium hydrogen phosphate was used as an ammonia standard; $777.5 \mathrm{mg}$ of diammonium hydrogen phosphate was dissolved in $100 \mathrm{ml}$ of water to give a solution containing $20 \mu \mathrm{l}$ of ammonia per $\mathrm{ml}$. This solution was diluted serially to obtain three standard solutions containing 20,10 , and $5 \mu \mathrm{g}$ of ammonia per $\mathrm{ml}$ respectively. These solutions were treated in the same way as the serum and synovial samples and a standard curve was constructed from which ammonia liberated from the serum and synovial fluid samples in 60 minutes could be determined, and the enzyme activity calculated. Enzyme activity was expressed as $\mathrm{U} / \mathrm{l}$ at $37^{\circ} \mathrm{C}$. All measurements were made in duplicate and Student's $t$ test was used to assess any statistical differences between experimental groups. Association of different parameters within each group was assessed by correlation coefficient analysis.

\section{Results}

Fig. 1 shows the adenosine deaminase activities

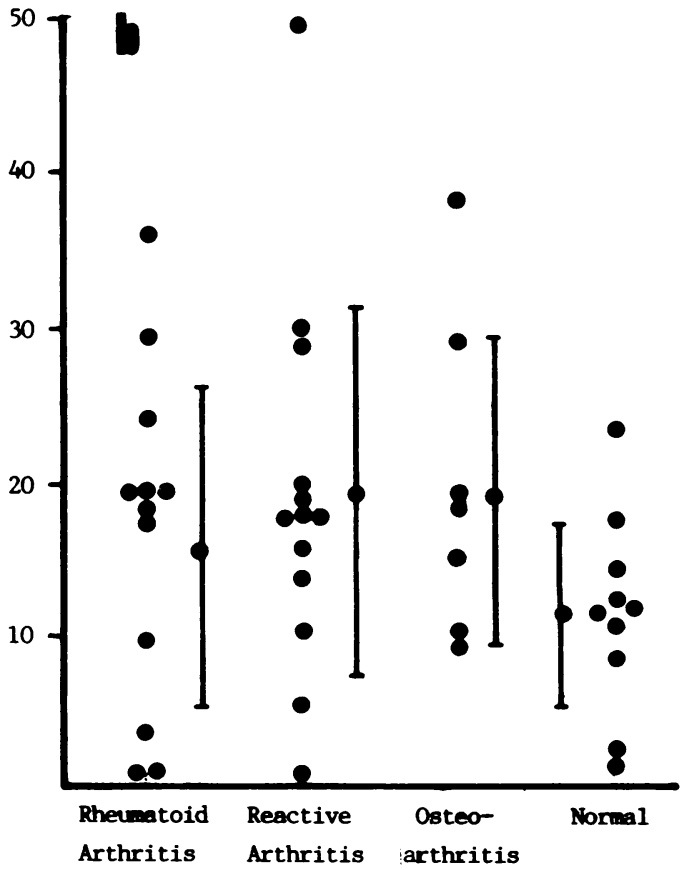

Fig. 1 (a) Synovial and (b) serum deaminase activities in patients with different types of arthritis. 
measured in serum and synovial fluid samples. Patients with rheumatoid arthritis had significantly increased ADA activity in their synovial fluids as compared with patients suffering from osteoarthritis and normal controls $(p<0.01)$. Patients with reactive arthritis also had significantly raised levels of ADA activity in their synovial fluids as compared with patients suffering from osteoarthritis and normal control subjects. The mean ADA activity measured in the synovial fluids of patients with rheumatoid and reactive arthritis was similar (21.5 (SD 8.4) and 18.5 (10.3) respectively) and there were no significant differences between groups ( $>0.05$ ). Although ADA activity in the synovial fluid of the osteoarthritic group was significantly less than that present in the synovial fluid of patients with rheumatoid or reactive arthritis, the mean value was higher than that of normal control subjects (Fig. 1a).

Serum ADA activity of all groups of patients with arthritis did not differ significantly from that of the normal controls $(p>0 \cdot 05)$. No significant differences between the groups could be shown (Fig. 1b). Comparison of synovial and serum ADA activities showed a significant association in the rheumatoid arthritis group $(r=0.82$ (SD 0.18$))$, but there was no significant association in the groups with osteoarthritis and reactive arthritis $(r=0 \cdot 39(0.41)$ and $0 \cdot 14$ $(0 \cdot 29)$ respectively).

As expected, synovial fluids obtained from patients with RA and reactive arthritis contained raised concentrations of protein and increased numbers of polymorphs and lymphocytes as compared with patients suffering from osteoarthritis (Table 1). There was, however, no significant association between the number of white cells and lymphocytes present in the synovial fluids and the synovial ADA activities $(r=0.0013 \quad(0.31)$ and $0.0076(0 \cdot 31)$ respectively). Similarly, no significant

Table 1 ADA activity and some laboratory parameters measured in the synovial fluid of patients with different types of arthritis

\begin{tabular}{llll}
\hline & $\begin{array}{l}\text { Rheumatoid } \\
\text { arthritis } \\
(n=12)\end{array}$ & $\begin{array}{l}\text { Reactive } \\
\text { arthritis } \\
(n=13)\end{array}$ & $\begin{array}{l}\text { Osteoarthritis } \\
(n=7)\end{array}$ \\
\hline $\begin{array}{l}\text { Mean (SD) protein } \\
\text { concentration (g/l) }\end{array}$ & $55.4(19)$ & $61.9(24)$ & $33.3(11)$ \\
$\begin{array}{l}\text { Mean (SD) number of } \\
\text { polymorphs } \\
\times 10^{-4} / 1\end{array}$ \\
$\begin{array}{l}\text { Mean (SD) number of } \\
\text { lymphocytes } \\
\times 10^{-4} / 1\end{array}$ \\
$\begin{array}{l}\text { Mean (SD) ADA activity } \\
\left(\mathrm{U} / 1 \text { at } 37^{\circ} \mathrm{C}\right)\end{array}$ & $3.9(5.9)$ & $4.2(8.5)$ & $0.61(1.2)$ \\
\hline
\end{tabular}

association was detected between the synovial glucose and protein concentrations and the synovial ADA activities.

\section{Discussion}

All nucleated cells contain adenosine deaminase. Distribution of this enzyme in different tissues, $\stackrel{\infty}{+}$ however, varies considerably, and it has been shown? that lymphoid organs, in particular the thymus, $\overrightarrow{\vec{\omega}}$ contain the highest level of enzyme activity. ${ }^{10} \mathrm{~W}$ Additionally, cortical thymocytes contain more ADA than medullary thymocytes, though peripheral lymphoid organs and lymphocytes, in general, contain less activity. ${ }^{11} 12$ Peripheral T lymphocytes have been shown to contain five to 20 times more $\mathrm{N}$ ADA activity than B lymphocytes ${ }^{12}{ }^{13}$ or non-T ando non- $B$ cells. It is possible, therefore, that determination of serum ADA activity, or activity in differentc tissues, and particularly activity in serous fluids, may be a useful indicator of the presence of increased lymphoreticular activities. Indeed, in patients witho typhoid fever, brucellosis, and infectious mononucleosis serum ADA activity has been found to be raised. ${ }^{14} 15$

The most useful application of the ADA deter-o mination, in terms of differential diagnosis, is inő patients with tuberculosis. First Piras et al and latero Ocana $e t a l^{7}$ and Martinez-Vazques et al showed that patients with tuberculous pericarditis had3 significantly higher enzyme activity than patients suffering from idiopathic pericarditis, neoplastic pericarditis, or pericarditis due to uraemia, systemicov lupus, or radiation.

Pettersson et al and Ocana et al also showed that pleural effusions caused by rheumatoid arthritis hach significantly raised ADA activity. ${ }^{3-5}$ Accordingly determination of ADA activity has been suggested as a means of discriminating between rheumatoids and tuberculous pleural effusions and those of other aetiologies. Identification of tuberculous pleuraE. effusion may be aided by the determination of complement activities ( $\mathrm{C} 3$ and $\mathrm{C} 4)$ and glucosen concentration in the pleural fluid. ${ }^{7}$

A raised level of ADA activity in the synovia $\omega$ fluid of patients with rheumatoid arthritis, there fore, is not an unexpected finding and might have् been expected to be a discriminative test fore identifying rheumatoid joint swellings. In this study however, we found high levels of ADA activity in rheumatoid synovial effusions, but patients with reactive arthritis also showed ADA activity that wasp increased almost to the same extent. Furthermore? as shown in Fig. 1, although osteoarthritic patients as a group had lower levels of ADA activity in theiß synovial fluids, this does not hold true for individuap 
cases, and this decreases the value of ADA determination in terms of differential diagnosis. Although measurement of synovial fluid ADA activity levels does not discriminate absolutely between joint swellings of different aetiologies, we feel that in certain instances it may be of some value in differentiating between osteoarthritis and rheumatoid or reactive arthritis.

\section{References}

1 Hovi T, Smyth J F. Allison A C, Williams S C. Role of adenosine deaminase in lymphocyte proliferation. Clin Exp Immunol 1976; 23: 395-403.

2 Shore A. Dosch H M. Gelfand E W. Role of adenosine deaminase in the early stages of precursor $\mathrm{T}$ cell maturation. Clin Exp Immunol 1981: 44: 152-5.

3 Pettersson T. Ojala K. Weber T H. Adenosine deaminase in the diagnosis of pleural effusions. Acta Med Scand 1984; 215: 299-304.

4 Pettersson T, Klockars M. Weber T. Pleural fluid adenosine deaminase in rheumatoid arthritis and systemic lupus erythematosus. Chest 1984: 86: 273.

5 Ocana I, Martínez-Vázquez J M. Ribera E. Capdevila J A. Fernandez de Sevilla T. Pleural fluid adenosine deaminase activity in rheumatoid arthritis and systemic lupus erythematosus. Chest 1984: 86: 273-4.

6 Martínez-Vázquez J M, Ribera E, Ocano I. Segura R.
Adenosine deaminase activity in tuberculous pericarditis. Thorax 1986; 41: 888-9.

7 Ocana I, Martínez-Vázquez J M. Segura R, Fernandez de Sevilla T. Adenosine deaminase in pleural fluids. Test for diagnosis of tuberculous pleural effusion. Chest 1983; 84: 51-3.

8 Piras M A, Gakis C. Budroni M, Andreoni G. Adenosine deaminase activity in pleural effusions. An aid to differential diagnosis. $\mathrm{Br}$ Med $\mathrm{J}$ 1978; ii: 1751-2.

9 Karger $\mathrm{H}$. Method for estimation of serum adenosine deaminase. Scand J Clin Lab Invest 1964: 16: 570-4.

10 Chechic B E, Schrader W P. Minowado J. An immunomorphologic study of adenosine deaminase distribution in human thymus tissue, normal lymphocytes and haemopoietic cell lines. J Immunol 1981; 126: 1003-7.

11 Macdermott R P, Tritsch G L, Formeister J F. Adenosine deaminase and nucleoside phosphorylase activities in normal human blood mononuclear cell subpopulation. Clin Exp Immunol 1980; 42: 303-7.

12 Sullivan J L, Osborn W R A, Wedgewood R J. Adenosine deaminase activity in lymphocytes. Br J Haematol 1977; 37: 157-8.

13 Shohat B, Agam G, Brosh S. Adenosine deaminase activity in lymphocyte subpopulations of B-16 melanoma and normal C57BC bearing mice. Immunol Lett 1984; 8: 307-10.

14 Galantini B, Nardiello S, Russo M, Fiorentino F. Increased lymphocyte adenosine deaminase in typhoid fever. Scand $J$ Infect Dis 1981: 13: 47-50.

15 Mejer J, Nygaard P, Cohn J, Gadeberg O. Adenosine deaminase, purine nucleoside phosphorylase and 5-nucleosidase activities in infectious mononucleosis. Adv Exp Med Biol 1984: 165: $249-52$. 